\title{
Age estimation comparison between whole and thin-sectioned otoliths and pelvic fin-ray sections of long-lived lake trout, Salvelinus namaycush, from Great Bear Lake, Northwest Territories, Canada
}

\author{
Colin P. Gallagher ${ }^{1} \cdot$ Rick J. Wastle $^{1} \cdot$ Julie R. Marentette ${ }^{2} \cdot$ Louise Chavarie $^{3} \cdot$ Kimberly L. Howland $^{1}$ (1)
}

Received: 21 October 2020 / Revised: 26 March 2021 / Accepted: 8 June 2021 / Published online: 16 July 2021

(c) Crown 2021

\begin{abstract}
Studies to determine precision and bias of both methods and age-readers are important to evaluate reliability of age data used for developing fisheries management objectives. We assessed within-reader, between-reader, and between-method precision (coefficient of variation, CV\%) and bias of age estimations for long-lived lake trout, Salvelinus namaycush, from Great Bear Lake using three readers with different levels of experience. The assessment used independent age estimates $(n=3$ per reader) from whole and transverse-sectioned otoliths (range $=1-67$ years), and pelvic fin-ray sections (range $=3-26$ years). We also examined between-method differences in assigned confidence scores. Within readers, age estimates from sectioned otoliths were more precise (2.6-3.0\%) than whole (3.6-4.5\%) otoliths. Between whole and sectioned otoliths, precision of age estimates was $5.4 \%$ and bias was low up to age 20 . Age was typically under-estimated from whole otoliths compared to sections for fish $\geq 34$ years. Increased reader confidence was correlated with greater precision and younger age estimates, particularly for whole otoliths, but less so for fin rays. Age was estimated with higher confidence from otolith sections than other methods. The least experienced reader estimated age with the lowest precision, and between-reader bias was evident among older ages. Age was consistently under-estimated and less precise from pelvic fins compared to sectioned otoliths, and are therefore an unsuitable non-lethal alternative. Sectioned otoliths revealed longevity was greater (67 years) than historically documented using whole otoliths (53 years) for these fish. Our findings contribute to those relying on otoliths or pelvic fin rays to estimate ages of long-lived lake trout populations, which are a key component of freshwater fauna in polar North America.
\end{abstract}

Keywords Bias $\cdot$ Precision $\cdot$ Otoliths $\cdot$ Pelvic fin rays $\cdot$ Confidence

\section{Introduction}

Age-based research into life-history, and population demographics and dynamics of teleost fishes typically relies on calcified structures (e.g., rays, spines, otoliths) to estimate age (Chilton and Beamish 1982; Kerns and LombardiCarlson 2017). Assessing and reducing age estimation

Kimberly L. Howland

kimberly.howland@dfo-mpo.gc.ca

1 Fisheries and Oceans Canada, 501 University Crescent, Winnipeg, MB R3T-2N6, Canada

2 Fisheries and Oceans Canada, 200 Kent Street, Ottawa, ON K1A-0E6, Canada

3 Scottish Centre for Ecology and the Natural Environment, University of Glasgow, Glasgow, UK error (process error and observation error; Campana 2001) is essential to determine the accuracy and precision of age information. Process error is a result of inconsistent patterns in the deposition of growth zones in a particular calcified structure that does not reflect the period of interest (e.g., annual) and produces inaccurate age estimates. Observation error is a result of uncertainty for a reader with the interpretation of growth zones associated with a particular age estimation method. This can lead to different age estimates from repeated independent counts (Campana 2001; McBride 2015).

Even if a structure and preparation method has been validated (using known-age fish or confirming annuli periodicity; Buckmeier et al. 2017), age comparison studies, either within-reader, between-reader, or between-method, based on multiple estimates from individual structures, are necessary to evaluate repeatability (i.e., precision) of age estimates. 
These age comparison studies also allow identification of bias, and selection of the most optimal structure and preparation method to minimize age estimation error (Campana et al. 1995). Estimating ages of long-lived species can be particularly challenging and complex because of their slower growth after sexual maturity that results in smaller spacing between annuli (Andrews et al. 2005; Campana et al. 2008; Hamel et al. 2015). Another factor influencing the quality of age data is reader experience, where less-experienced readers tend to produce less precise estimates, particularly with species or structures that are difficult to read (Campana and Moksness 1991; Rude et al. 2013; Oele et al. 2015). To address issues related to experience, readers can subjectively codify their personal level of certainty using pre-determined criteria for each age estimate with a reader confidence (i.e., readability) score to identify an estimate that may be biased or less accurate (Fitzgerald et al. 1997; Spiegel et al. 2010). Using inaccurate or imprecise age data could result in biased population parameter estimates, and the resulting consequences on management decisions can have detrimental effects on the sustainability of a fishery and/or population (Lai and Gunderson 1987; Reeves 2003; Tyszko and Pritt 2017). This is particularly true for slowgrowing, late-maturing, and long-lived species that would face a longer recovery period after significant declines in population status (Juan-Jordá et al. 2015).

The lake trout (Salvelinus namaycush) is a large, slow growing, long-lived and mainly lacustrine salmonid adapted to cold and oxygen-rich habitats, and whose endemic distribution ranges between $\sim 41$ and $74^{\circ} \mathrm{N}$ (Scott and Crossman 1973). The species is important for commercial, recreational, and Indigenous subsistence fisheries, and many populations have been or are currently being examined to assess population status and characterize life history (e.g., Hansen et al. 2008; Nieland et al. 2008; McDermid et al. 2010; Chavarie et al. 2013). Lake trout are particularly vulnerable to overharvest as a result of their life history characteristics (Healey 1978; Schuter et al. 1998; Post et al. 2002; Kaufman et al. 2009). Given the species' importance to various fisheries, accurate and precise age estimates are necessary for science advice to support fisheries management and conservation objectives.

In earlier years ( 1940s-1970s), scales were commonly used to estimate age of lake trout, but were eventually shown to substantially under-estimate age of older fish compared to otoliths (Miller and Kennedy 1948; Dubois and Langeux 1968; Sharp and Bernard 1988). Examples of maximum age obtained reading lake trout scales was 23 years ("with reasonable certainty") up to 37 years (with low certainty) in Great Bear Lake, Northwest Territories, Canada (Miller and Kennedy 1948), 12 years in Lake Mistassini, Québec, Canada (Dubois and Langueux 1968), and 19-20 years in Summit Lake, Alaska, U.S.A.
(Sharp and Bernard 1988). Power (1978) examined whole otoliths (lateral surface) from long-lived Arctic lake trout where for larger otoliths a lateral grind was performed to expose the inner rings and a hotplate was occasionally used to bake otoliths to clarify the outer rings. In some instances, these extra preparation steps helped to produce age estimates $>50$ years. Historical between-method comparison studies mainly focused on evaluating scales and otoliths that were either read whole (Sharp and Bernard 1988; Burnham-Curtis and Bronte 1996; Schram and Fabrizio 1998; and references therein) or thin-sectioned along the transverse plane (Casselman and Gunn 1992). Annual periodicity of growth increments for lake trout has been validated for otolith sections to an age of at least 50 years (Campana et al. 2008) and maxilla sections between ages 3 and 27 (Wellenkamp et al. 2015).

For lake trout, the precision and bias of age estimation structures and preparation methods have rarely been evaluated based on one or more reads of a single sample using multiple age-readers (see Sharp and Bernard 1988; Murphy et al. 2018). However, an age comparison study using a wide range of multiple paired reads from individual fish that includes age estimates $>30$ years using whole and thinsectioned otoliths, and pelvic fin-ray sections has not been conducted. Campana et al. (2008) compared age estimates of sectioned lake trout otoliths, which included very old fish ( $>50$ years), to assess bias and precision between dissecting (reflected light at 16-40x magnification) and compound (transmitted light at magnifications up to 160x) microscopes based on a single read.

This study used samples from Great Bear Lake, a location where lake trout can attain ages $>50$ years (Falk et al. 1974; Chavarie et al. 2016). Multiple age-readers produced three independent age estimates from whole otoliths, and transverse thin-sectioned otoliths and pelvic fins. The objectives of our study were to: (1) determine if whole otoliths provide a reliable alternative to thin-sectioned otoliths, particularly at younger ages, and (2) determine if pelvic fins provide a suitable non-lethal age estimation alternative to thin-sectioned otoliths. We sought to achieve our objectives by evaluating precision and bias, and assessing confidence: (1) between otolith preparation methods and between agereaders, and (2) between thin-sectioned otoliths and pelvic fins and between age-readers. This study is relevant for the management and conservation of Great Bear Lake's exceptional intraspecific diversity of lake trout, which supports a subsistence and world-class trophy fishery (mainly catch and release) (Howland and Tallman 2005; Chavarie et al. 2013). Furthermore, the findings should be pertinent for all laboratories, stock assessment programs, research facilities, and fisheries management agencies that have relied on otoliths or pelvic fin rays (e.g., Mills et al. 2002) to estimate ages of long-lived lake trout populations. 


\section{Materials and methods}

\section{Study area}

Great Bear Lake, located on the Canadian Arctic Circle between $65^{\circ}$ and $67^{\circ} \mathrm{N}$ latitude, is a five-armed, cold, and ultra-oligotrophic freshwater lake (Fig. 1). The lake's volume $\left(>2200 \mathrm{~km}^{3}\right)$, surface area $\left(>31,000 \mathrm{~km}^{2}\right)$ and depth $(>400 \mathrm{~m})$, make it the largest lake entirely within Canada and the fourth largest lake in North America (Johnson 1975a; Rao et al. 2012). The lake is typically ice covered between November and June (Rao et al. 2012). The predominant fish species encountered in gill net fisheries in Great Bear Lake are lake trout, lake whitefish (Coregonus clupeaformis), and lake cisco (Coregonus artedi) (Johnson 1975b, Howland unpublished data). Other large-bodied species include walleye (Sander vitreus), burbot (Lota lota), northern pike (Esox lucius), longnose sucker (Catostomus catostomus), Arctic grayling (Thymallus arcticus), and round whitefish (Prosopium cylindraceum) typically comprise $<5 \%$ of gill net catches (Johnson 1975b; Howland unpublished data). Located in the Sahtu Settlement Area, Great Bear Lake is considered to be a relatively pristine ecosystem with only one community situated on its shores (Délìnę; population 576) (Evans 2000; Howland and Tallman 2005; GNWT 2020).

\section{Sample collection}

Lake trout were collected as part of ongoing fisheries assessment studies on Great Bear Lake during 2000-2016 using overnight gillnet sets (see Howland et al. 2013; Chavarie et al. 2018 for details of net configuration and procedures). Sagittal otoliths and pelvic fin rays were collected from captured fish sampled for comprehensive biological

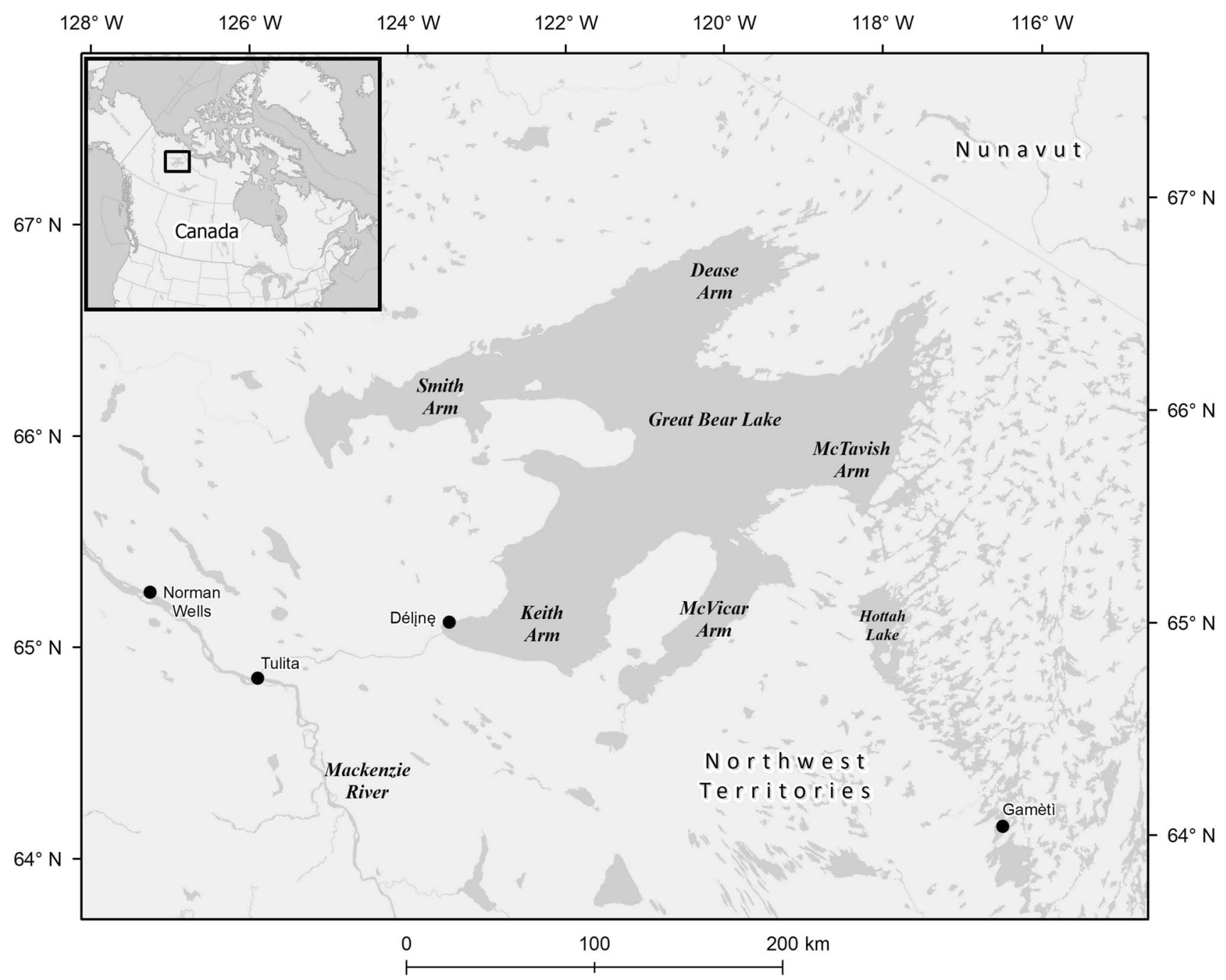

Fig. 1 Map of Great Bear Lake, Northwest Territories, Canada 
information. Otoliths were removed, cleaned, and stored dry in labeled envelopes. The first three rays of the left pelvic fin were cut at the base using bone cutters, excised, and left to dry in labeled envelopes.

\section{Preparation of structures and age estimation}

Otoliths were read whole by placing them in a small waterfilled glass petri dish, lateral side up, over a black background and interpreted under a Leica MZ12.5 or a Nikon SMZ1000 dissecting microscope at magnifications of 10-80x with reflected light. The lateral surface of lake trout otolith is convex, and consequently the centre area of larger ones is thicker and opaque. Therefore, a slight grind was performed by hand on this surface for medium-to-large otoliths only (i.e., $>\sim 6 \mathrm{~mm}$ long), using a 1000-grit wet stone to expose the nucleus and inner few annuli. Also, to help clarify the remaining annuli, large otoliths were pre-soaked in water for 4 to $24 \mathrm{~h}$.

Otolith and pelvic fin-ray sections were prepared as described by Chavarie et al. (2016) and Zhu et al. (2015), respectively. Otoliths were embedded with the sulcus side up in ColdCure Epoxy Resin (Industrial Formulators of Canada Ltd.). After hardening, the otolith was viewed with the sulcus side down under a dissecting microscope equipped with a cross-hair micrometer eyepiece, and the nucleus was demarcated using an ultra-fine tip marker. With the crosshair centered on the nucleus, a section line was then chosen through the nucleus and the best area of the dorsal lobe, close to the transverse plane. Dots were placed on the epoxy above and below the otolith along that line. Using the dots on the epoxy as a guide, a Buehler Isomet low-speed saw (Lake Bluff, Illinois, U.S.A.) with two diamond wafering blades separated by a $0.5 \mathrm{~mm}$ spacer was used to obtain the section. These sections were examined in a manner similar to whole otoliths using the same microscopes (15-100x) and lighting. Pelvic fin rays were trimmed, embedded in ColdCure Epoxy Resin, and sectioned from the proximal end at a thickness of $0.35 \mathrm{~mm}$ with the low-speed saw. Three fin sections were typically taken and affixed to labeled microscope slides. Fin sections were also viewed using the same equipment as the whole otolith reads, at 15-80x magnification (although they were not immersed in water). Annuli were identified based on criteria described by Chilton and Beamish (1982).

\section{Study design}

To address the stated objectives, analyses were linked to one of two study designs. For objective 1, otoliths of lake trout (fork length range $=69-1136 \mathrm{~mm}$ ) collected from the multiple arms of Great Bear Lake between 2008 and 2016 were used to compare bias and precision of the two otolith preparation methods for a wide range of age estimates (1 to $\sim 67$ years) using two experienced age-readers (Reader 1 and Reader 2). Otoliths from latter sampling years were selected as these were directly accessible to both readers in the age estimation laboratory and also provided multiple samples of lake trout $>50$ years of age. The samples used for this part of this study had been previously processed, which means that one otolith of each pair had already been sectioned. Consequently, only one otolith was available to the readers for whole reads (also referred as 'surface reads'). Both readers read whole $(n=199)$ and sectioned otoliths $(n=252)$ three times each, blind to results from previous reads or estimates by the other reader. Sufficient time was allowed to pass between successive reads (several days to weeks) to ensure readers were not familiar with individual samples from one read to the next. Sample size differed between readers because either one age-reader was unable to provide an age estimate or the sample was lost between the readers (whole otolith: Reader $1 n=189$, Reader $2 n=199$; sectioned otolith: Reader $1 n=250$, Reader $2 n=252$ ). A confidence score was assigned to each age estimate by both age-readers: 1 (very good; no interpretation issues and would expect high repeatability every time), 2 (fairly good; few interpretation issues and would expect high repeatability most of the time), 3 (fair; some interpretation issues with moderate level of repeatability), 4 (fairly poor; interpretation is fairly difficult and low amount of repeatability), and 5 (poor; interpretation is difficult and very low amount of repeatability). Therefore, a high score implied reduced reader confidence in the accuracy of an age estimate.

For objective 2, sectioned otoliths and pelvic fins from lake trout (fork length range $=207-1075 \mathrm{~mm}$ ) collected in 2000 were used to compare bias and precision between structures using two age-readers (Reader 1 and Reader 3 ). The range of the age estimates based on otolith reads was 6 to 41 years. Both readers read sectioned otoliths and pelvic fins three times each, again allowing sufficient time between successive reads to prevent reader familiarization of samples, blind to results from previous reads or estimates by the other reader. Sample size was not equal between age-readers because some samples were lost or damaged between the readers (sectioned otolith: Reader $1 n=172$, Reader 3 $n=175$; pelvic fin: Reader $1 n=194$, Reader $3 n=193$ ). Only the confidence scores provided by Reader 1 for both structures were used as Reader 3 did not use a similar criteria in assessing confidence.

Reader 1 had the most experience estimating the age of lake trout among the three readers ( $>30$ years of experience; 22 years with lake trout otoliths). Reader 1 trained Reader 2 (6 years of experience including 200 annual lake trout otolith samples) and both worked in the same age estimation laboratory. Reader 3 worked in an independent laboratory 
and had the least experience (5 years of experience; 4 years sporadic experience with salmonid species).

\section{Statistical analysis}

We used age bias plots (Campana et al. 1995) to illustrate the consistency of age estimates between readers for each preparation method (otolith) and structure, and between preparation methods (otolith) and structures for each reader. The bias plots include error bars representing the $95 \%$ confidence interval around the mean age assigned by one reader for all fish assigned an age by a second reader where confidence intervals that are either equal to zero or very narrow indicates consistency in repeated age estimates (Campana 1995). Additionally, we used the Evans-Hoenig test to evaluate bias based on the diagonal symmetry of an age-agreement table where a significant $P$-value indicated that differences among reads (i.e., between readers and methods for this study) were due to bias and not random error (Evans and Hoenig 1998; McBride 2015). However, the Evans-Hoenig symmetry test cannot reliably detect bias when precision is low; therefore, the test was not performed in instances when the coefficient of variation (see below) was $>10$ (McBride 2015). The Evans-Hoenig test was designed to detect signed differences (i.e., +1 vs. -1 year) for paired-age data across multiple age classes and performs well compared to other tests of symmetry (McBride 2015). Precision (i.e., repeatability of reads and expressed as \%) was measured by calculating the coefficient of variation (CV) (Chang 1982; Campana 2001) :

$C V_{j}=100 \times \frac{\sqrt{\sum_{i=1}^{R} \frac{\left(X_{i j}-X_{j}\right)^{2}}{R-1}}}{X_{j}}$

where $R$ is the number of times each sample was read, $X_{\mathrm{j}}$ is the average age estimate of the jth fish, and $X_{\mathrm{ij}}$ is the ith age estimate for the jth fish. Higher $\mathrm{CV}$ values reflect decreased precision. Data used to create age bias plots and to calculate Evans-Hoenig tests of symmetry and CV were generated using the FSA (Fisheries Stock Assessment) package in R (Ogle 2016). To evaluate within-reader repeatability among ages, the median age of each triplicate reading was plotted against mean $\mathrm{CV}$ for that age and a Spearman rho $(\rho)$ nonparametric correlation was used to test whether $\mathrm{CV}$ was positively correlated with age.

We also tested for differences between methods (otolith preparation, and sectioned otoliths vs. pelvic fins) and between readers using non-parametric Wilcoxon signed-rank tests $(\mathrm{V})$ for paired data. To assess differences in reader confidence scores, we used a chi-square test to evaluate frequencies of median confidence scores between otolith preparation methods and between sectioned otoliths and pelvic fins separately for each reader (except Reader 3 ). We did not test for differences in confidence between readers given the subjective nature of assigning confidence. For Reader 1 and Reader 2, Spearman rho nonparametric correlation was used to determine if reader confidence scores and CVs were correlated, and if reader confidence scores and age estimates were correlated. All statistics were performed in RStudio (version 1.1.442) with R (version 3.5.0; R Core Team 2018) and considered significant if $\rho<0.05$.

\section{Results}

\section{Whole versus sectioned otoliths}

Age estimates were more precise and more confident from sectioned otoliths than whole otoliths for both readers. Age estimates from whole otoliths were more precise for Reader $2(\mathrm{CV}=3.6 \%)$ than Reader $1(\mathrm{CV}=4.5 \%)$ (Table 1). Confidence scores for estimated ages (mean \pm SD) from whole otoliths were similar between readers (Reader $1=2.4 \pm 0.93$; Reader $2=2.0 \pm 0.94)$ and were strongly and significantly positively correlated with both CV (Reader $1 \rho=0.73$; Reader $2 \rho=0.67$ ) and age estimates (Reader 1 $\rho=0.72$; Reader $2 \rho=0.78$ ) (Table 2). Whole otolith age and CV were significantly positively correlated for both readers (Reader $1 \rho=0.59$; Reader $2 \rho=0.70$ ) with relatively high $\mathrm{CV}$ values $(>5 \%)$ predominantly observed in age estimates $\geq 20$ years for Reader 1 and $\geq 23$ years for Reader 2 (Table 2; Fig. 2). Age estimates from sectioned otoliths were more precise for Reader $1(\mathrm{CV}=2.6 \%)$ than Reader 2 $(\mathrm{CV}=3.0 \%)$ (Table 1). Confidence scores for estimated ages (mean \pm SD) from sectioned otoliths were similar between readers (Reader $1=2.0 \pm 0.59$; Reader $2=2.0 \pm 0.67$ ) and significantly positively correlated to both CV (Reader $1 \rho=0.53$; Reader $2 \rho=0.50$ ) and age estimates (Reader $1 \rho=0.43$; Reader $2 \rho=0.61$ ) (Table 2). Sectioned otolith age and CV were significantly positively correlated for both readers (Reader $1 \rho=0.68$; Reader $2 \rho=0.51$ ) with relatively high $\mathrm{CV}$ values becoming more prevalent among ages $>35$ years for both readers (Table 2; Fig. 2).

Between-reader comparisons for both whole and sectioned otoliths revealed bias among older ages where agreement was highest from sectioned otoliths. Ages estimated from whole and sectioned otoliths by both readers generally agreed between ages 1 and 37 (Fig. 3). For lake trout $>37$ years from whole and sectioned otoliths methods, age estimates by Reader 1 were consistently older than Reader 2, with average differences of 10-17 years observed from whole otoliths (Fig. 3). Variability in repeated age estimates from sectioned otoliths increased after age 38, although bias was low up to age 58 (Fig. 3). At ages $\geq 60$ years using sectioned otoliths, Reader 1 tended 
Table 1 Coefficient of variation $(\mathrm{CV}, \%)$, test statistic and significance $(P$-value) of Evans-Hoenig $(\mathrm{E}-\mathrm{H})$ test for symmetry, and sample size $(n)$ of within-reader, between-reader, and between-methods/ structure comparisons whole and transversely thin-sectioned otoliths, and between thin-sectioned otoliths and pelvic fin rays of lake trout from Great Bear Lake, Northwest Territories, Canada

\begin{tabular}{|c|c|c|c|c|c|}
\hline Comparison & Otolith preparation/structure & Reader & $\mathrm{CV}$ & $\mathrm{E}-\mathrm{H}$ & $n$ \\
\hline \multirow[t]{8}{*}{ Whole and sectioned otoliths } & Whole otoliths & 1 & 4.5 & & 189 \\
\hline & Whole otoliths & 2 & 3.6 & & 199 \\
\hline & Sectioned otoliths & 1 & 2.6 & & 250 \\
\hline & Sectioned otoliths & 2 & 3.0 & & 252 \\
\hline & Whole otoliths & 1 vs 2 & 4.7 & $X=18.2,15, P=0.2535$ & 188 \\
\hline & Sectioned otoliths & 1 vs 2 & 3.3 & $X=27.7,14, P=0.0156$ & 250 \\
\hline & Whole vs section & 1 & 5.5 & $X=78.3,21, P<0.0001$ & 186 \\
\hline & Whole vs section & 2 & 5.3 & $X=129.0,22, P<0.0001$ & 197 \\
\hline \multirow[t]{8}{*}{ Sectioned otoliths and pelvic fins } & Sectioned otoliths & 1 & 2.4 & & 172 \\
\hline & Sectioned otoliths & 3 & 7.9 & & 175 \\
\hline & Sectioned pelvic fins & 1 & 4.3 & & 194 \\
\hline & Sectioned pelvic fins & 3 & 7.9 & & 193 \\
\hline & Sectioned otoliths & 1 vs 3 & 7.5 & $X=31.2,11, P=0.001$ & 172 \\
\hline & Sectioned pelvic fins & 1 vs 3 & 12.0 & $*$ & 193 \\
\hline & Sectioned otoliths vs pelvic fins & 1 & 14.7 & $*$ & 167 \\
\hline & Sectioned otoliths vs pelvic fins & 3 & 24.0 & * & 167 \\
\hline
\end{tabular}

E-H test performed for between-reader and -methods/structure comparisons

*Evans-Hoenig test not performed when CV > 10 (McBride 2015)

Table 2 Spearman's rank correlation coefficient $(\rho)$, degrees of freedom (d.f.), and $P$-value between age-reader confidence score* (median) and coefficient of variation (CV), between age-reader confidence score (median) and estimated age, and between age (median of three independent reads) and CV using whole otoliths, and transversely thin-sectioned otoliths and pelvic fin rays of lake trout from Great Bear Lake, Northwest Territories, Canada

\begin{tabular}{|c|c|c|c|c|c|c|c|c|c|c|c|}
\hline \multirow[t]{2}{*}{ Comparison } & \multirow[t]{2}{*}{ Structure } & \multirow[t]{2}{*}{ Reader } & \multicolumn{3}{|c|}{ Confidence and CV } & \multicolumn{3}{|c|}{ Confidence and age } & \multicolumn{3}{|c|}{ Age and CV } \\
\hline & & & $\rho$ & d.f. & $P$ & $\rho$ & d.f. & $P$ & $\rho$ & d.f. & $P$ \\
\hline \multirow[t]{4}{*}{ Whole and sectioned otoliths } & Whole otoliths & 1 & 0.73 & 200 & $<0.0001$ & 0.72 & 234 & $<0.0001$ & 0.59 & 48 & $<0.0001$ \\
\hline & Whole otoliths & 2 & 0.67 & 199 & $<0.0001$ & 0.78 & 199 & $<0.0001$ & 0.70 & 46 & $<0.0001$ \\
\hline & Sectioned otoliths & 1 & 0.53 & 251 & $<0.0001$ & 0.43 & 250 & $<0.0001$ & 0.68 & 55 & $<0.0001$ \\
\hline & Sectioned otoliths & 2 & 0.50 & 251 & $<0.0001$ & 0.61 & 252 & $<0.0001$ & 0.51 & 53 & $<0.0001$ \\
\hline \multirow[t]{4}{*}{ Sectioned otoliths and pelvic fins } & Sectioned otoliths & 1 & 0.43 & 170 & $<0.0001$ & 0.30 & 170 & $<0.0001$ & 0.36 & 27 & $<0.0001$ \\
\hline & Sectioned otoliths & 3 & & - & - & - & - & - & -0.20 & 22 & 0.33 \\
\hline & Sectioned pelvic fins & 1 & 0.32 & 192 & $<0.0001$ & 0.38 & 192 & $<0.0001$ & 0.38 & 20 & $<0.0001$ \\
\hline & Sectioned pelvic fins & 3 & - & - & - & - & - & - & -0.27 & 15 & 0.0003 \\
\hline
\end{tabular}

*Reader 3 confidence scores not used because criteria were not consistent with Reader 1

to estimate older ages than Reader 2 (Fig. 3). The EvansHoenig test between readers was statistically significant for sectioned otoliths only, indicating high symmetry between readers for whole otoliths, while precision was higher for sectioned otoliths $(\mathrm{CV}=3.3 \%)$ compared to whole otoliths $(\mathrm{CV}=4.7 \%)$ (Table 1). The Wilcoxon matched-pairs tests demonstrated significant differences in age estimates between readers for both methods (Table 3).

Ages estimated by both readers from whole and sectioned otoliths were relatively free of bias and highly precise from ages 1 to $\sim 20$ (Fig. 4). Variation between readers increased slightly between age 21 and 38 (section reads). Whole otolith reads beyond $\sim 33$ years were consistently younger than sectioned otolith reads in most cases. Average differences between methods were approximately 8 years, although differences of over 20 years were sometimes observed for individuals with sectioned otolith age estimates $\geq 50$ years (Fig. 4). The Evans-Hoenig test of symmetry between methods was significant for both readers indicating systematic bias in reading sectioned otoliths multiple times; however, 


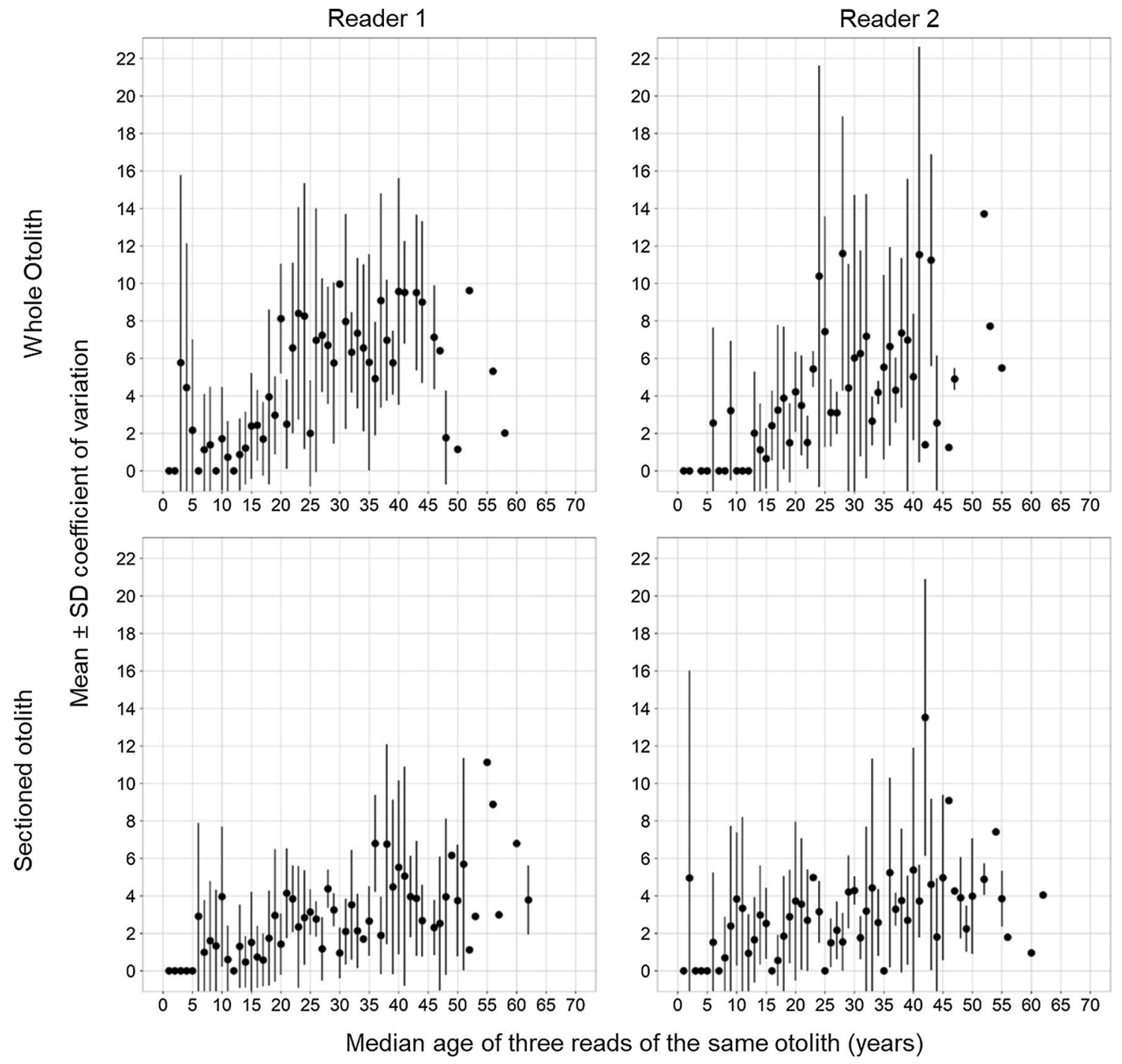

Fig. 2 Mean and standard deviation of coefficient of variation (CV, $\%$ ) plotted against median age estimated from three independent reads of the same otolith for two age-readers examining whole and trans-

precision was similar for both readers $(\mathrm{CV}=\sim 5.4 \%)$ (Table 1). The Wilcoxon matched-pairs tests demonstrated significant differences in age estimates between methods for both readers (Table 3). Reader confidence differed significantly between preparation methods for Readers 1 (Chisquare test, $\left.X^{2}{ }_{6}=113.5, P<0.0001\right)$ and 2 (Chi-square test, $\left.X^{2}{ }_{6}=62.9, P<0.0001\right)$ with greater frequencies of high confidence scores (i.e., 1-2) from age estimates based on otolith sections (Table 4).

\section{Sectioned otoliths versus sectioned pelvic fins}

Age estimates were more precise and more confident from sectioned otoliths than pelvic fins for Reader 1, while reader experience had an important effect on precision of ages for versely thin-sectioned otoliths of lake trout from Great Bear Lake, Northwest Territories, Canada

both structures. Precision of age estimates from otolith sections was higher for Reader $1(\mathrm{CV}=2.4 \%)$ than Reader 3 $(\mathrm{CV}=7.9 \%)$ (Table 1). The confidence score (mean $\pm \mathrm{SD})$ for sectioned otoliths for Reader 1 was $2.3 \pm 0.79$, and a weak statistically significant positive correlation was observed between the reader's confidence score and CV $(\rho=0.43)$ as well as age $(\rho=0.30)$ (Table 2). Precision of age estimates from pelvic fins was higher for Reader $1(\mathrm{CV}=4.3 \%)$ than Reader $3(\mathrm{CV}=7.9 \%)$ (Table 1$)$. The confidence score (mean \pm SD) for pelvic fins for Reader 1 was $2.5 \pm 0.96$, and a weak significant positive correlation was observed between the reader's confidence score and CV $(\rho=0.32)$ and age $(\rho=0.38)$ (Table 2$)$. While a weak yet statistically significant positive correlation was also detected between sectioned otolith age and CV for Reader 


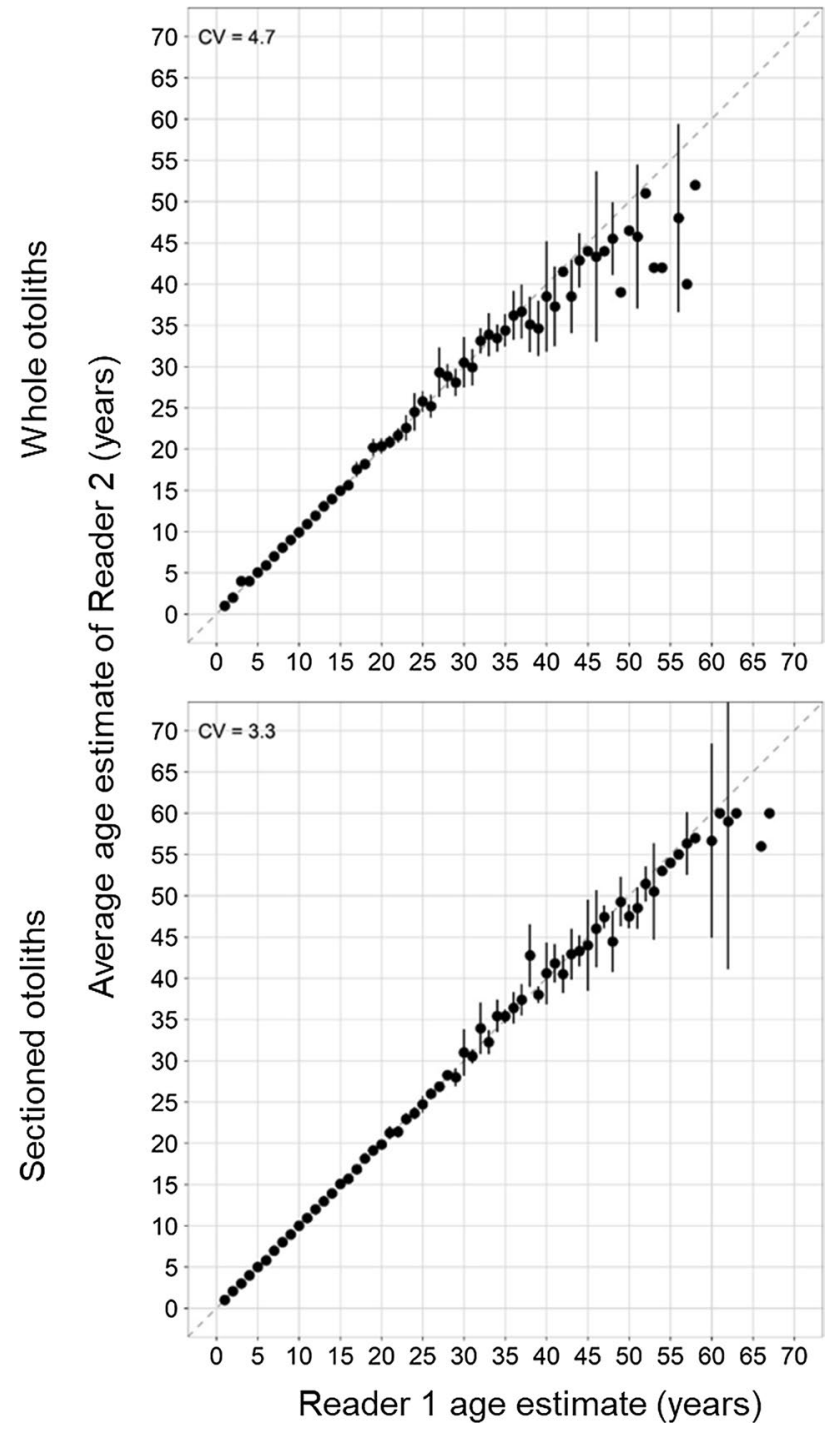

Fig. 3 Between-reader age bias plots of whole and transversely thinsectioned otolith preparation methods for two different age-readers using lake trout from Great Bear Lake, Northwest Territories, Canada. Each error bar represents $95 \%$ confidence intervals. Dashed diagonal line is the $1: 1$ line. Coefficient of variation $(\mathrm{CV}, \%)$ in the top left of each panel

$1(\rho=0.36)$, no statistically significant relationship was observed for Reader 3 ( $\rho=-0.20$ ) (Table 2; Fig. 5).

Age estimate comparisons between readers from sectioned otoliths were relatively unbiased between ages 8 and 24 , whereas those by Reader 3 tended to be slightly older for ages $6-7$ and considerably younger for ages $\geq 25$ years (Fig. 6). Ages estimated by Reader 3 from pelvic fins were consistently younger than those estimated by Reader 1 among all ages, and bias increased after age 10 (Fig. 6). Between-reader precision was higher for sectioned otoliths $(\mathrm{CV}=7.5 \%)$ than pelvic fins $(\mathrm{CV}=12.0 \%)$. Significant differences were observed between readers in the test of
Table 3 Wilcoxon matched-pairs test $(\mathrm{V})$ and $P$-value of betweenreader and between-method/structure comparisons using whole otoliths and transversely thin-sectioned and pelvic fin rays of lake trout from Great Bear Lake, Northwest Territories, Canada

\begin{tabular}{llrr}
\hline Comparison & Reader & \multicolumn{1}{l}{ V } & \multicolumn{1}{l}{$P$} \\
\hline Whole otoliths & 1 vs 2 & 20639 & $<0.0001$ \\
Sectioned otoliths & 1 vs 2 & 26727 & 0.0037 \\
Whole vs. sectioned otoliths & 1 & 16695 & $<0.0001$ \\
Whole vs. sectioned otoliths & 2 & 9522 & $<0.0001$ \\
Sectioned otoliths & 1 vs 3 & 48499 & $<0.0001$ \\
Sectioned pelvic fins & 1 vs 3 & 142585 & $<0.0001$ \\
Sectioned otoliths vs. pelvic fins & 1 & 122084 & $<0.0001$ \\
Sectioned otoliths vs. pelvic fins & 3 & 124173 & $<0.0001$ \\
\hline
\end{tabular}

symmetry for sectioned otoliths only and for matched-pairs of age estimates for both structures (Tables 1 and 3 ).

Age was consistently under-estimated from pelvic fins by both readers when compared to otolith sections (Fig. 7). The bias was parallel to the 1:1 line up to age $\sim 20$ (otolith) when the relationship changed and the bias plots demonstrated the inability of pelvic fin sections to reasonably estimate age for older lake trout (Fig. 7). CV values were the poorest among all comparisons in this study with Reader 1 having greater precision $(\mathrm{CV}=14.7 \%)$ compared to Reader $3(\mathrm{CV}=24 \%)$. The matched-pairs tests indicated statistically significant differences between methods for both readers (Table 3). Reader confidence differed significantly between structures for Reader 1 (Chi-square test, $X_{8}^{2}=119.2, P<0.0001$ ) with greater frequencies of low confidence scores (i.e., 3-5) observed for pelvic fin sections (Table 4). A weak statistically significant positive and negative correlation was detected between pelvic fin age and CV for Reader 1 $(\rho=0.38)$ and Reader $3(\rho=-0.27)$, respectively (Table 2; Fig. 5). CV tended to be relatively high among pelvic fin ages $>20$ years for Reader 1 and considerably higher among ages $<11$ years for Reader 3 (Fig. 5).

\section{Discussion}

We demonstrated that the otolith preparation method used affected bias, precision, and reader confidence, particularly for older fish ( $\geq \sim 34$ years; whole method), when estimating ages of lake trout from Great Bear Lake. We also found that pelvic fin-ray sections were a poor non-lethal alternative to otoliths throughout the age range examined. Sectioning was the superior otolith preparation method that produced the greatest precision within and between readers with relatively low $\mathrm{CV}$ across a wide range of ages. We note, however, that readers only had one otolith from each pair available for whole otolith reads, where the previously sectioned otolith may have been the preferred one for these reads at times. 


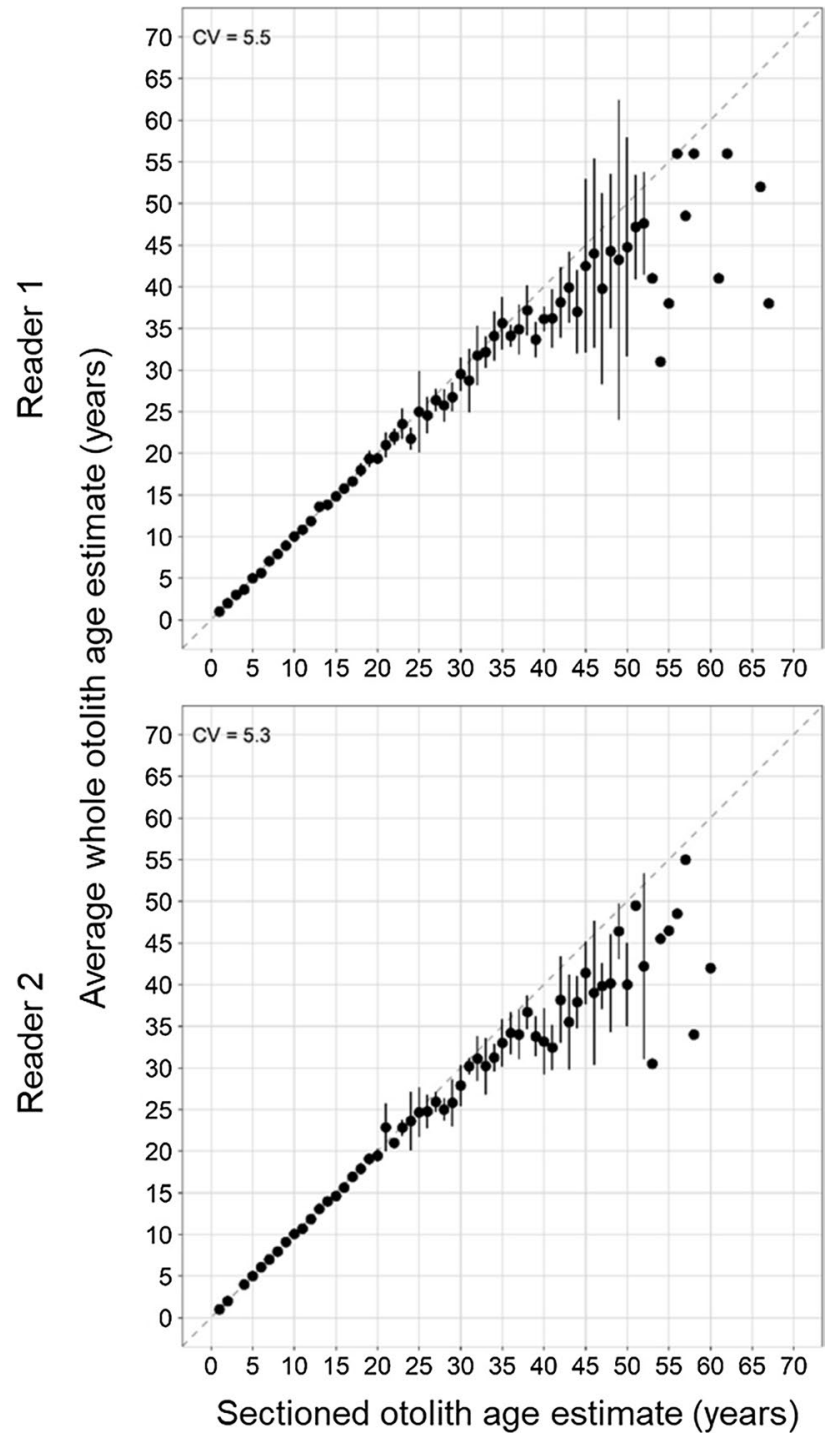

Fig. 4 Between-method age bias plots of whole and transversely thinsectioned otolith preparation methods for two different age-readers using lake trout from Great Bear Lake, Northwest Territories, Canada. Each error bar represents 95\% confidence intervals. Dashed diagonal line is the 1:1 line. Coefficient of variation $(\mathrm{CV}, \%)$ in the top left of each panel
Ideally, both otoliths from each fish would be available for whole reads before sectioning. The transverse otolith section was the structure and preparation method used to validate age of long-lived lake trout in Arctic lakes (Campana et al. 2008) and our results confirm the method's suitability to provide accurate, precise, and confident age estimates for lake trout with proper training (e.g., mentorship and use of reference collection) and adequate experience.

Nonetheless, our study demonstrated that the whole otolith method could provide accurate, precise, and confident age estimates for lake trout over a relatively young age range. The whole method provides robust and repeatable age estimates that are almost identical to the thin-sectioned method between ages 1 and 20 for experienced readers (Fig. 4). Therefore, a proposed age estimation protocol for lake trout populations inhabiting ultra-oligotrophic or slightly more productive lakes would be to use experienced readers to read otoliths using the whole method up to age 20 and section any beyond that age. If this protocol was applied to the otolith data from this study, the combined-method CV from both experienced readers would be similar to that obtained from sections alone $(3.1 \%$ and $2.1 \%$ compared to $2.6 \%$ and $3.0 \%$, respectively). Furthermore, we suggest that any otoliths $\leq 20$ years (whole) with low confidence should also be sectioned, given the increased likelihood of generating age estimates with higher confidence. Using a protocol that allows for not having to section every otolith would save preparation time and money for consumables (e.g., epoxy; Muir et al. 2008; Williams et al. 2015). Based on all the lake trout age data accumulated from the Great Bear Lake fisheries-independent sampling conducted by Fisheries and Oceans Canada between 2008 and 2016 (years examined for otolith preparation comparison; $n=2114$ samples), about half of the age estimates could have been from whole otoliths. Although other studies are required to determine if age 20 is an appropriate threshold for when to section otoliths from other lake trout populations, we posit that that the threshold is likely to be very similar for other populations inhabiting ultra-oligotrophic or slightly more productive Arctic and subarctic systems.
Table 4 Percent frequency of confidence scores assigned by two age-readers (Reader 1 and 2) to age estimates obtained from whole and transversely thin-sectioned otoliths, and thinsectioned otoliths and pelvic fin rays (Reader 1 only) using lake trout from Great Bear Lake, Northwest Territories, Canada

\begin{tabular}{|c|c|c|c|c|c|c|c|}
\hline \multirow[t]{2}{*}{ Score } & \multirow[t]{2}{*}{ Confidence } & \multicolumn{2}{|c|}{ Reader $1(\%)$} & \multicolumn{2}{|c|}{ Reader $2(\%)$} & \multicolumn{2}{|c|}{ Reader $1(\%)$} \\
\hline & & Whole & Section & Whole & Section & Section & Pelvic* \\
\hline 1 & Very good & 19.0 & 16.8 & 16.1 & 19.0 & 20.3 & 16.1 \\
\hline 2 & Fairly good & 34.4 & 72.0 & 44.7 & 63.5 & 32.0 & 34.4 \\
\hline 3 & Fair & 39.7 & 10.8 & 23.1 & 17.5 & 47.1 & 34.4 \\
\hline 4 & Fairly poor & 6.9 & 0.4 & 16.1 & 0 & 0.6 & 14.1 \\
\hline 5 & Poor & 0 & 0 & 0 & 0 & 0 & 1.0 \\
\hline Total sample size & & 198 & 250 & 199 & 252 & 170 & 192 \\
\hline
\end{tabular}

*Total $\mathrm{n}=$ does not equal to Table 1 as confidence score was not assigned for two samples 


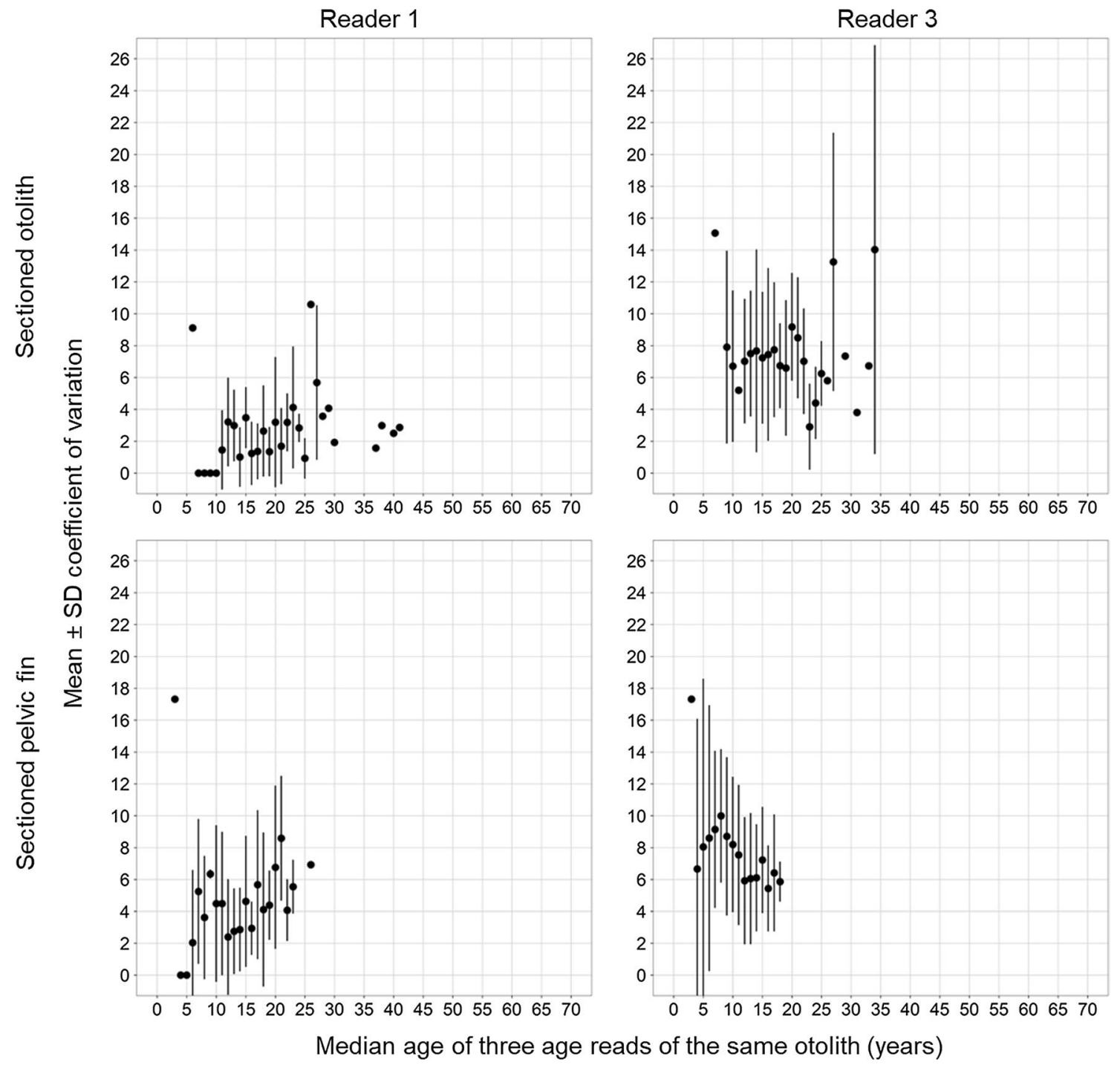

Fig. 5 Mean and standard deviation of coefficient of variation (CV, $\%)$ plotted against median age estimated from three independent reads of the same otolith for two age-readers examining transversely thin-

Our conclusion that age of older lake trout cannot be estimated accurately from whole otoliths agrees with Campana et al. (2008), who discussed how earlier studies likely underestimated lake trout ages using this method. Similar conclusions regarding whole versus sectioned otolith methods have been made for other long-lived species (Beamish 1979; Winkler et al. 2019). Experienced readers in our study (Readers 1 and 2) clearly interpreted annuli differently toward the margin of whole otoliths for lake trout $\geq 35$ years (Fig. 3). Although neither reader had extensive experience with whole otoliths in this age range, they were both challenged by outer annuli that cannot be attributed to experience level alone. Confidence and precision were both strongly correlated with lake trout age that decreased as age estimates increased. This observation underscores the uncertainty sectioned otoliths and pelvic fin rays of lake trout from Great Bear Lake, Northwest Territories, Canada

associated with ages estimated from whole otoliths for older ages. Sectioning otoliths produced over twice as many age estimates $\geq 50$ years compared to the whole method $(5.5 \%$ vs $2.2 \%$ of all age estimates) and a greater maximum age (67 vs 59 years).

The estimated longevity of lake trout of 67 years from Great Bear Lake in this study is greater than previously thought. Historically, longevity was estimated to be 53 years based on studies conducted in the 1970s and 1980s that only used laterally ground whole otoliths viewed under a dissecting microscope (Falk et al. 1974; Yaremchuk 1986), which likely underestimated population longevity. Our study had some of the oldest age estimates for lake trout ever recorded (see McDermid et al. 2010 (suppl.); Hansen et al. 2021) and had a similar maximum age to the lake trout from Great 


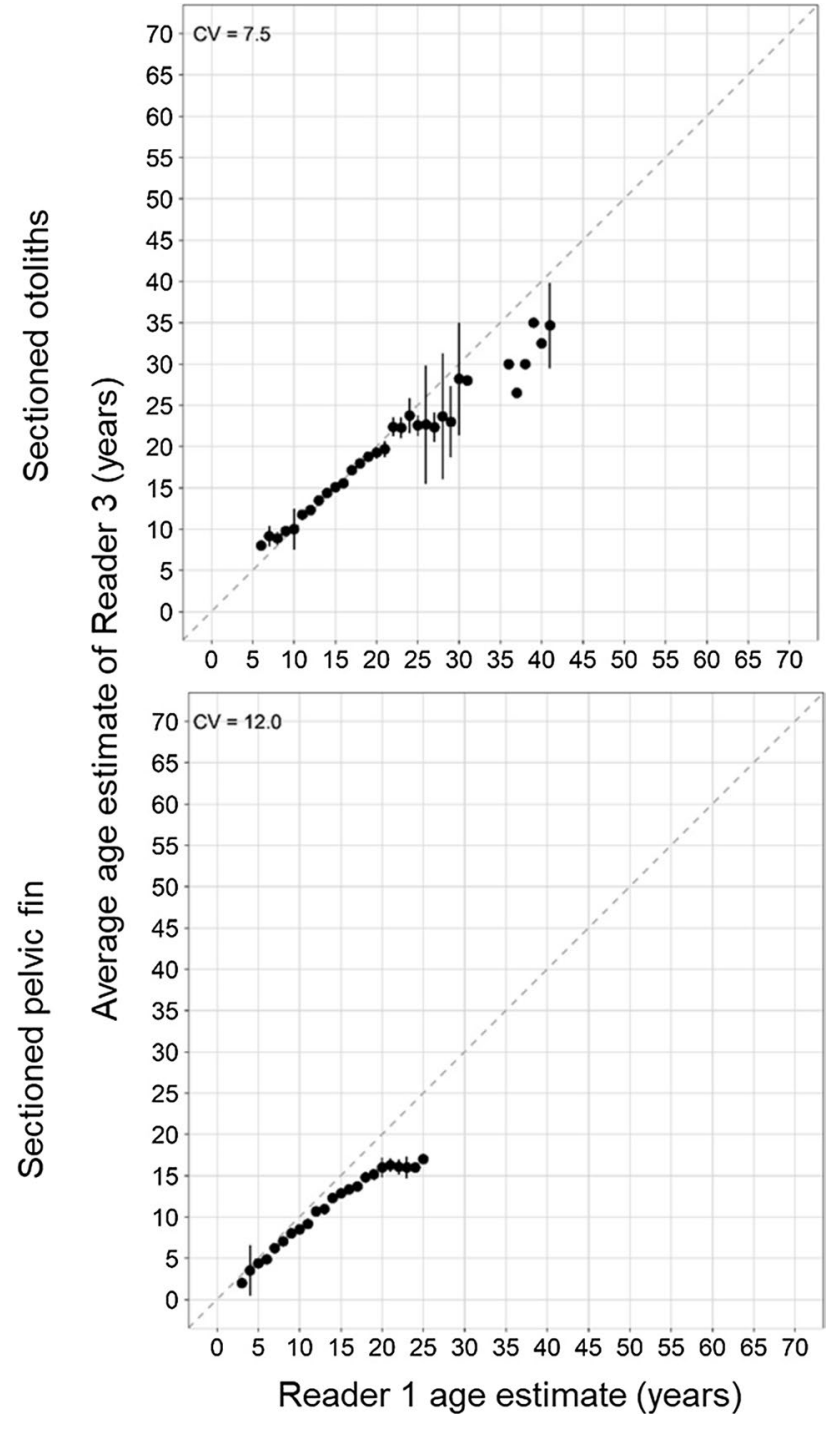

Fig. 6 Between-reader age bias plots of transversely thin-sectioned otoliths and pelvic fin rays for two different age-readers using lake trout from Great Bear Lake, Northwest Territories, Canada. Each error bar represents $95 \%$ confidence intervals. Dashed diagonal line is the $1: 1$ line. Coefficient of variation $(\mathrm{CV}, \%)$ in the top left of each panel

Bear Lake examined by Chavarie et al. (2016) (60 years) and Chavarie et al. (2018) and Hansen et al. (2021) (68 years) who also used sectioned otoliths.

The readability of annuli on otolith sections of older lake trout can be affected by many factors, including microscope type and magnification, section polishing (Campana et al. 2008), choice of section plane, cutting precision, and the positioning and lighting of the section ( $\mathrm{R}$. Wastle, personal observation). Clarity of annuli of older age classes examined along the ventral sulcus edge (described as 'dorsal' in the text) of sectioned otoliths was improved when polished and viewed under a compound microscope (at 160x) with transmitted light (Campana et al. 2008). We focused on choosing

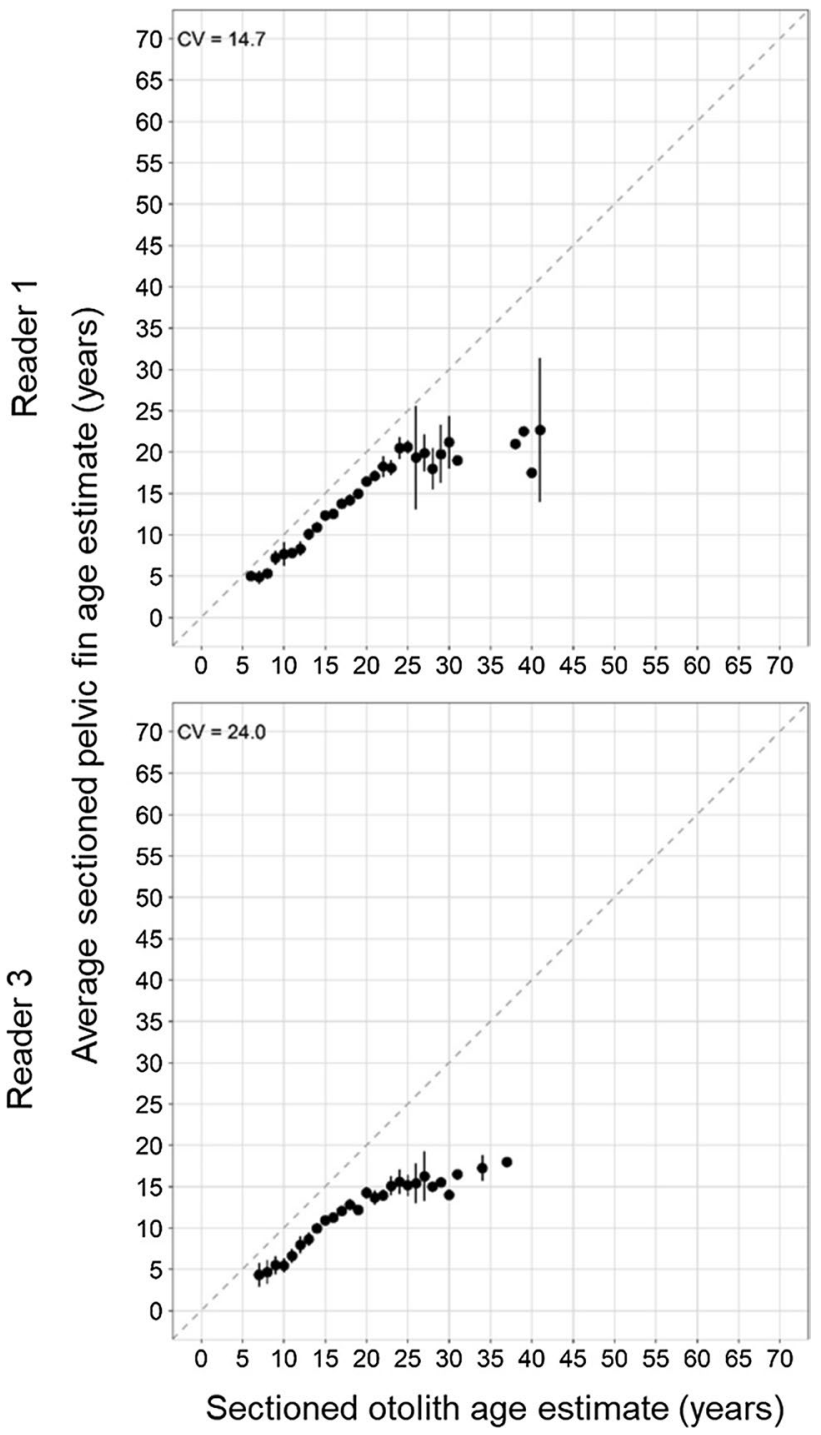

Fig. 7 Between-method age bias plots of transversely thin-sectioned otoliths and pelvic fin rays for two different age-readers using lake trout from Great Bear Lake, Northwest Territories, Canada. Each error bar represents 95\% confidence intervals. Dashed diagonal line is the 1:1 line. Coefficient of variation $(\mathrm{CV}, \%)$ in the top left of each panel

the best section plane through the dorsal lobe of the otoliths, close to the true transverse plane, to create sections that were readable out to the dorsal tip, which is the longest transect from nucleus to edge (Online Resource 1). A longer transect means greater separation between outer annuli of older samples. Consequently, readers were able to read these samples beyond age 60 with reasonable confidence using dissecting microscopes (up to 100x) and reflected light.

Our findings indicate that pelvic fin-ray sections, prepared and viewed as in our study, should not be used to estimate the ages of lake trout from Great Bear Lake. Age estimates from pelvic fin-ray sections yielded age estimates of the lowest 
average reader confidence (Reader 1) and yet were relatively reproducible within readers (higher $\mathrm{CV}$ than sectioned otoliths, except for Reader 3; as discussed below). Interestingly, reproducibility of age estimates improved among older ages of pelvic fins examined by Reader 3, which suggests that the reader had difficulties delineating annuli in younger ( $<11$ years) lake trout. The weak correlation between Reader 1 confidence and both $\mathrm{CV}$ and age estimates of pelvic fin sections indicated that higher confidence demonstrated by an experienced age-reader was not strongly associated with better precision, and that generally lower confidence values were observed among all age classes. Comparison of otolith and pelvic fin-ray sections age estimates produced considerably higher $\mathrm{CV}$ values than the $\mathrm{CV}=5 \%$ precision target threshold suggested by Campana (2001). Pelvic fin-ray sections consistently underestimated age relative to otolith sections up to $\sim 20$ years and could not be used to reliably discern older age classes. Similarly, pelvic and pectoral fin rays produced less precise and younger age estimates than whole or sectioned otoliths for Dolly Varden (Salvelinus malma) (Gallagher et al. 2016). Reader confidence, precision and maximum age estimate ( $<12$ years) were also lower for pectoral fin rays than for broken and burnt otoliths of lake whitefish from Great Slave Lake (Zhu et al. 2015). Pectoral and anal fin rays also tended to underestimate ages compared to whole otoliths in Arctic Grayling (Sikstrom 1983), while anal and pectoral fin rays produced quite variable age estimates that were typically younger than broken and burnt otoliths of Arctic char (Salvelinus alpinus) and Dolly Varden (Barber and McFarlane 1987). Alternatively, pectoral fin rays and broken and burnt otoliths produced very similar age estimates in inconnu (Stenodus leucichthys) (Howland et al. 2004). In temperate North American locations, dorsal fin rays were less precise than broken and burnt otoliths of lake whitefish from Lake Champlain (Herbst and Marsden 2011) and pectoral fin rays were less precise than whole otoliths of brook trout (Salvelinus fontinalis; Stolarksi and Hartman 2008). Ages estimated from sectioned otoliths did not differ from those of pelvic fin rays of lake whitefish from Lake Michigan (age range $=5-13$ years) although pelvic fins tended to under-estimate ages $\geq 10$ years (Muir et al. 2008). Similarly, ages estimated from pelvic fin rays were similar to those of sectioned otoliths of lake whitefish from the Experimental Lakes Area (age range $=3-19$ years), where fin rays have long been used to estimate ages of various species including lake trout (Mills et al. 2002; Mills and Chalanchuk 2004). In Europe, high agreement and low bias was observed between pectoral fin rays and thin-sectioned otoliths (age range $=2-6$ years) of Peipsi whitefish (Coregonus maraenoides) from Bulgaria (Uzunova et al. 2020). Although further age validation research is required, it is possible that fin rays may provide a suitable alternative to otoliths among a wider range of relatively younger ages for some species from faster-growing and shorter-lived populations in more temperate climates.

Reader experience affected precision and bias of lake trout age estimates. Reader 3 had the least experience and the lowest precision for sectioned otoliths and pelvic fins compared to highly experienced Reader 1 . One might expect better precision with sectioned otoliths compared to fin rays given the within-reader results of the two highly experienced readers, and the multiple examples of between-structure comparisons cited above; however, this was not the case for the less-experienced Reader 3. Challenges in the reproducibility of sectioned otolith reads were evident for Reader 3 , particularly among older age classes. Clearly, readers 1 and 3 were interpreting otolith annuli differently for ages 6 to 7 and $>20$ where mean differences of $>5$ years were observed in older age classes. Similarly, between-reader bias of pelvic fin section reads revealed the readers were interpreting annuli differently among all sampled age classes, with a mean difference of 1 year between ages 3 and $\sim 10$, which gradually increased thereafter. These results emphasize the need for proper training and sharing of reference material among laboratories (Campana 2001; Buckmeier et al. 2017), particularly for long-lived species where extremely small increments between outer annuli of older fish can challenge accurate and precise age estimation.

Our study revealed that a highly experienced reader can produce precise age estimates over a wide range of otolith ages for lake trout from Great Bear Lake, which has the greatest longevity recorded for this species. While sectioning was the best overall otolith preparation method, the most efficient protocol without sacrificing quality would be to use a combination of whole and section methods, where whole otoliths are used to estimate age of fish up to age 20 and sections are used for older fish. Multiple lake trout ecotypes that inhabit Great Bear Lake exhibit differences in adult growth, age- and size-at-maturity, fecundity, and longevity (Chavarie et al. 2016) that could influence the spacing and readability of otolith annuli. Therefore, evaluating precision, bias, and age-reader confidence among ecotypes would be beneficial to advance conservation objectives for these lake trout. The development of ecotype-specific age estimation protocols could benefit other populations as phenotypic and life history diversity of lake trout is prevalent in large and deep lakes throughout its range (Chavarie et al. 2021). Assessing the impacts of fisheries in Great Bear Lake requires reliable age estimates that would also ideally minimize sampling mortalities of the very large $(>\sim 900 \mathrm{~mm})$ and presumably old lake trout (we note that very large lake trout are not necessarily the oldest; Chavarie et al. 2016) from both the trophy fishery that primarily targets large fish, and fishery-independent surveys (using gill nets) that target a wide range of sizes. While such an approach to sampling would encourage the sustainability of the trophy fishery and 
support the request from Indigenous co-management partners to limit mortality of large fish that are still alive when gill nets are retrieved, our results suggest pelvic fins are not a suitable non-lethal alternative. Until such an alternative is discovered, otoliths are currently the best-known structure to produce reliable age estimates for population assessment and life history studies of long-lived lake trout inhabiting Great Bear Lake. The findings of our study on lake trout from Great Bear Lake are pertinent for all laboratories that have relied on otoliths or pelvic fin rays to estimate ages of slow-growing and long-lived lake trout populations, which are a key component of the freshwater fauna across much of polar North America.

Supplementary Information The online version contains supplementary material available at https://doi.org/10.1007/s00300-021-02901-9.

Acknowledgements We appreciate the financial support provided by the Fisheries and Oceans Canada (DFO) Sahtu Implementation Fund, Sahtu Renewable Resources Board, Aboriginal Affairs and Northern Developement Canada/Government of Northwest Territories Cumulative Impact Monitoring Program. We acknowledge the Délìnę Renewable Resources Council for their continued support over the years. We also sincerely appreciate the involvement of various technicians and camp support from Délìnę (Darryl Betsidea, Isodore Betsidea, Maurice Betsidea, Bruce Kenny, Darren Kenny, Greg Kenny, George Menacho, Bobby Modeste, Brent Taniton, Allison Tatti, Gerald Tutcho, Archie Vital, Barbara Yukon, Charity Yukon, Chris Yukon, Cyre Yukon, Mary Rose Yukon), staff from DFO (Kristin Adair, Dave Boguski, Heather Clark, Les Harris, Kristin Hynes, Michel LeClaire, Brendan Malley, Simon Wiley) and volunteers (Jean-Guy Chavarie) that collected biological data. Logistical support was provided by the Polar Continental Shelf Program. The age-readers used for this study were Rick Wastle, Lenore Vandenbyllaardt, and Jason Friesen. The map in figure 1 was produced by Adriana Rivas Ruis (DFO). We appreciate comments and editorial suggestions from Michael Hansen, Heidi Swanson, and an anonymous reviewer that improved the manuscript.

Author contributions KLH, CPG and RJW conceived and designed the study. KLH, LC, and CPG contributed to the data acquisition in the field. CPG and JRM analyzed the data. CPG, JRM, RJW and KLH interpreted results. KLH led proposals to secure funding for the study. CPG, JRM, and RJW wrote the manuscript, and all authors reviewed and edited it.

\section{Declarations}

Conflict of interest None of the authors have a financial or non-financial conflict of interest regarding this research. The fish that were sampled were handled based on guidelines approved by the Canadian Council of Animal Care.

Open Access This article is licensed under a Creative Commons Attribution 4.0 International License, which permits use, sharing, adaptation, distribution and reproduction in any medium or format, as long as you give appropriate credit to the original author(s) and the source, provide a link to the Creative Commons licence, and indicate if changes were made. The images or other third party material in this article are included in the article's Creative Commons licence, unless indicated otherwise in a credit line to the material. If material is not included in the article's Creative Commons licence and your intended use is not permitted by statutory regulation or exceeds the permitted use, you will need to obtain permission directly from the copyright holder. To view a copy of this licence, visit http://creativecommons.org/licenses/by/4.0/.

\section{References}

Andrews AH, Burton EJ, Kerr LA, Cailliet GM, Coale KH, Lundstrom CC, Brown TA (2005) Bomb radiocarbon and lead-radium disequilibria in otoliths of bocaccio rockfish (Sebastes paucispinis): a determination of age and longevity for a difficult-to-age fish. Mar Freshw Res 56:517-528. https://doi.org/10.1071/MF04224

Barber WE, McFarlane GA (1987) Evaluation of three techniques to age Arctic Char from Alaskan and Canadian waters. Trans Am Fish Soc 116:874-881. https://doi.org/10.1577/1548-8659(1987) 116\%3c874:EOTTTA\%3e2.0.CO;2

Beamish RJ (1979) Differences in the age of Pacific hake (Merluccius productus) using whole otoliths and sections of otoliths. J Fish Res Board Can 36:141-151. https://doi.org/10.1139/f79-023

Buckmeier DL, Sakaris PC, Schill DJ (2017) Validation of annual and daily increments in calcified structures and verification of age estimates. In: Quist MC, Isermann DA (eds) Age and growth of fishes: principles and techniques. Am Fish Soc. Bethesda, Maryland, pp 33-79

Burnham-Curtis MK, Bronte CR (1996) Otoliths reveal a diverse age structure for humper lake trout in lake superior. Trans Am Fish Soc 125:844-851. https://doi.org/10.1577/1548-8659(1996)125\% 3c0844:ORADAS\%3e2.3.CO;2

Campana SE (2001) Accuracy, precision and quality control in age determination, including a review of the use and abuse of age validation methods. J Fish Biol 59:197-242. https://doi.org/10. 1111/j.1095-8649.2001.tb00127.x

Campana SE, Moksness E (1991) Accuracy and precision of age and hatch date estimates from otolith microstructure examination. ICES J Mar Sci 48:303-316. https://doi.org/10.1093/icesjms/ 48.3.303

Campana SE, Annand MC, McMillan JI (1995) Graphical and statistical methods for determining the consistency of age determinations. Trans Am Fish Soc 124:131-138. https://doi.org/10.1577/ 1548-8659(1995)124\%3c0131:GASMFD\%3e2.3.CO;2

Campana SE, Casselman JM, Jones CM (2008) Bomb radiocarbon chronologies in the Arctic, with implications for the age validation of lake trout (Salvelinus namaycush) and other Arctic species. Can J Fish Aquat Sci 65:733-743. https://doi.org/10.1139/f08-012

Casselman JM, Gunn JM (1992) Dynamics in year-class strength, growth, and calcified-structure size of native lake trout (Salvelinus namaycush) exposed to moderate acidification and whole-lake neutralization. Can J Fish Aquat Sci 49(S1):102-113. https://doi. org/10.1139/f92-305

Chang WYB (1982) A statistical method for evaluating the reproducibility of age determination. Can J Fish Aquat Sci 39:1208-1210. https://doi.org/10.1139/f82-158

Chavarie L, Howland KL, Tonn WM (2013) Sympatric polymorphism in lake trout: the coexistence of multiple shallow-water morphotypes in Great Bear Lake. Trans Am Fish Soc 142:814-823. https://doi.org/10.1080/00028487.2013.763855

Chavarie L, Howland KL, Venturelli P, Kissinger BC, Tallman R, Tonn W (2016) Life-history variation among four shallow-water morphotypes of lake trout from Great Bear Lake, Canada. J Great L Res 42:193-203. https://doi.org/10.1016/j.jglr.2015.07.006

Chavarie L, Howland KL, Harris LN, Hansen MJ, Harford WJ, Gallagher CP, Baillie SM, Malley B, Tonn WM, Muir AM, Krueger CC (2018) From top to bottom: do lake trout diversify along 
a depth gradient in Great Bear Lake, NT, Canada? PLoS ONE 13(3):e0193925. https://doi.org/10.1371/journal.pone.0193925

Chavarie L, Adams CE, Swanson HK, Ridgway MS, Tonn WM, Wilson CC (2021) Ecological diversity. In: Muir AM, Krueger CC, Hansen MJ, Riley SC (eds) The lake charr Salvelinus namaycush: biology, ecology, distribution, and management. Fish and Fisheries Series. Springer, Dordrecht, The Netherlands, pp 69-117

Chilton DE, Beamish RJ (1982) Age determination methods for fishes studied by the groundfish program at the pacific biological station. Can Spec Publ Fish Aquat Sci 60:1-102

Dubois A, Langeux R (1968) Comparative study of the age as determined by scales and otoliths of the lake trout (Salvelinus namaycush) of Lake Mistassini, Quebec. Nat Can 95: 907-928 [translated from French]. https://waves-vagues.dfo-mpo.gc.ca/Library/ 124373.pdf. Accessed 30 Jan 2021

Evans GT, Hoenig JM (1998) Testing and viewing symmetry in contingency tables, with application to readers of fish ages. Biometrics 54:620-629. https://www.jstor.org/stable/3109768. Accessed 6 Aug 2020

Evans MS (2000) The large lake ecosystems of northern Canada. Aquat Ecosyst Health Manag 3:65-79. https://doi.org/10.1080/14634 980008656992

Falk MR, Gillman DV, Dahlke LW (1974) Data on the biology of lake trout from Great Bear and Great slave lakes, Northwest Territories, 1973. Can Fish Mar Serv Data Rep Ser CEN/D-74-4

Fitzgerald TJ, Margenau TL, Copes FA (1997) Muskellunge scale interpretation: the question of aging accuracy. North Am J Fish Mange 17:206-209. https://doi.org/10.1577/1548-8675(1997) 017\%3c0206:MSITQO\%3e2.3.CO;2

Gallagher CP, Howland KL, Wastle RJ (2016) A comparison of different structures and methods for estimating age of northernform Dolly Varden Salvelinus malma malma from the Canadian Arctic. Polar Biol 39:1257-1265. https://doi.org/10.1007/ s00300-015-1848-Z

GNWT (Government of the Northwest Territories) (2020) Délìne Statistical Profile. NWT Bureau of Statistics. https://www.stats nwt.ca/community-data/infrastructure/deline.html. Accessed 4 August 2020.

Hamel MJ, Pegg MA, Goforth RR, Phelps QE, Steffensen KD, Hammen JJ, Rugg ML (2015) Range-wide age and growth characteristics of shovelnose sturgeon from mark-recapture data: implications for conservation and management. Can J Fish Aquat Sci 72:71-82. https://doi.org/10.1139/cjfas-2014-0238

Hansen MJ, Horner NJ, Liter M, Peterson MP, Maiolie MA (2008) Dynamics of an increasing lake trout population in Lake Pend Oreille, Idaho. North Am J Fish Manage 28:1160-1171. https:// doi.org/10.1577/M07-149.1

Hansen MJ, Guy CS, Bronte CR, Nate NA (2021) Life history and population dynamics. In: Muir AM, Krueger CC, Hansen MJ, Riley SC (eds) The lake charr Salvelinus namaycush: biology, ecology, distribution, and management. Fish and Fisheries Series. Springer, Dordrecht, The Netherlands, pp 253-286

Healey MC (1978) The dynamics of exploited lake trout populations and implications for management. J Wildl Manage 42(2): 307328. https://www.jstor.org/stable/3800268. Accessed 30 Mar 2020

Herbst SJ, Marsden JE (2011) Comparison of precision and bias of scale, fin ray, and otolith age estimates for lake whitefish (Coregonus clupeaformis) in Lake Champlain. J Great L Res 37:386-389. https://doi.org/10.1016/j.jglr.2011.02.001

Howland KL, Tallman RL (2005) Management of lake char in Great Bear Lake, Canada: historical perspectives and future directions. In: Kruse GH, Gallucci VF, Hay DE, Perry RI, Peterman RM, Shirley TC, Spencer PD, Wilson B, Woodby D (eds) Fisheries assessment and management in data-limited situations. Alaska Sea Grant, University of Alaska Fairbanks, Fairbanks, pp 141-159. https://doi.org/10.4027/famdis.2005.09
Howland KL, Gendron M, Tonn WM, Tallman RF (2004) Age determination of a long-lived coregonid from the Canadian North: comparison of otoliths, fin rays, and scales in inconnu (Stenodus leucichthys). Ann Zool Fenn 41:205-214

Howland K, Gallagher C, Boguski D, Chavarie L, Reist J, Rosenburg B, Wiley S (2013) Variation in morphology, life history and ecology of cisco in Great Bear Lake, Northwest Territories, Canada. DFO Can Sci Advis Sec Res Doc. 2013/106. https://cat.fsl-bsf.scitech. gc.ca/record=4017383 S6. Accessed 1 Mar 2020

Johnson L (1975a) Physical and chemical characteristics of Great Bear Lake, Northwest Territories. J Fish Res Bd Can 32:1971-1987. https://doi.org/10.1139/f75-234

Johnson L (1975b) Distribution of fish species in Great Bear Lake, Northwest Territories, with reference to zooplankton, benthic invertebrates, and environmental conditions. J Fish Res Bd Can 32:1989-2004. https://doi.org/10.1139/f75-235

Juan-Jordá MJ, Mosqueira L, Freire J, Dulvy NK (2015) Population declines of tuna and relatives depend on their speed of life. Proc R Soc B 282:20150322. https://doi.org/10.1098/rspb.2015.0322

Kaufman SD, Snucins E, Gunn JM, Selinger W (2009) Impacts of road access on lake trout (Salvelinus namaycush) populations: regional scale effects of overexploitation and the introduction of smallmouth bass (Micropterus dolomieu). Can J Fish Aquat Sci 66:212-223. https://doi.org/10.1139/F08-205

Kerns JA, Lombardi-Carlson LA (2017) History and importance of age and growth information. In: Quist MC, Isermann DA (eds) Age and growth of fishes: principles and techniques. Am Fish Soc. Bethesda, Maryland, pp 1-8

Lai HL, Gunderson DR (1987) Effects of ageing errors on estimates of growth, mortality and yield per recruit for walleye pollock (Theragra chalcogramma). Fish Res 5:287-302. https://doi.org/ 10.1016/0165-7836(87)90048-8

McBride RS (2015) Diagnosis of paired age agreement: a simulation approach of accuracy and precision effects. ICES J Mar Sci 72:2149-2167. https://doi.org/10.1093/icesjms/fsv047

McDermid JL, Shuter BJ, Lester NP (2010) Life history differences parallel environmental differences among North American lake trout (Salvelinus namaycush) populations. Can J Fish Aquat Sci 67:314-325. https://doi.org/10.1139/F09-183

Miller RB, Kennedy WA (1948) Observations on the lake trout of Great Bear Lake. J Fish Res Bd Can 7:176-189. https://doi.org/ 10.1139/f47-019

Mills KH, Chalanchuk SM (2004) The fin-ray method of aging lake whitefish. Ann Zool Fenn 41:215-223. https://www.jstor.org/ stable/23736205. Accessed 15 Mar 2020

Mills KH, Chalanchuk SM, Allen DJ (2002) Abundance, annual survival, and recruitment of unexploited and exploited lake charr, Salvelinus namaycush, populations at the experimental lakes area, Northwestern Ontario. Env Biol Fish 64:281-292. https:// doi.org/10.1023/A:1016058705612

Muir AM, Sutton TM, Peeters PJ, Claramunt RM, Kinnunen RE (2008) An evaluation of age estimation structures for lake whitefish in Lake Michigan: selecting an ageing method based on precision and a decision analysis. North Am J Fish Manage 28:1928-1940. https://doi.org/10.1577/M08-014.1

Murphy EW, Smith ML, He JX, Wellenkamp W, Barr E, Downey PC, Miller KM, Meyer KA (2018) Revised fish aging techniques improve fish contaminant trend analyses in the face of changing Great Lakes food webs. J Great L Res 44:725-734. https://doi. org/10.1016/j.jglr.2018.05.006

Nieland JL, Hansen MJ, Seider MJ, Deroba JJ (2008) Modeling the sustainability of lake trout fisheries in eastern Wisconsin waters of Lake Superior. Fish Res 94:304-314. https://doi.org/ 10.1016/j.fishres.2008.07.005

Oele DL, Lawson ZJ, McIntyre PB (2015) Precision and bias in aging northern pike: comparisons among four calcified structures. 
North Am J Fish Manage 35:1177-1184. https://doi.org/10. 1080/02755947.2015.1099579

Ogle DH (2016) Introductory fisheries analyses with R. CRC Press, Boca Raton, Florida

Post JR, Sullivan M, Cox S, Lester NP, Walters CJ, Parkinson EA, Paul AJ, Jackson L, Shuter BJ (2002) Canada's recreational fisheries: the invisible collapse? Fisheries 27:6-17. https://doi. org/10.1577/1548-8446(2002)027\%3c0006:CRF\%3e2.0.CO;2

Power G (1978) Fish population structure in Arctic lakes. J Fish Res Bd Can 35:53-59. https://doi.org/10.1139/f78-008

R Core Team (2018) R: A language environment for statistical computing. R Foundation for Statistical Computing, Vienna, Austria. http://www.R-project.org. Accessed 1 Dec 2019

Rao YR, Huang A, Schertzer WM, Rouse WR (2012) Modelling of physical processes and assessment of climate change impacts in Great Bear Lake. Atmos Ocean 50:317-333. https://doi.org/ 10.1080/07055900.2012.668492

Reeves SA (2003) A simulation study of the implications of age reading errors for stock assessment and management advice. ICES J Mar Sci 60:314-328. https://doi.org/10.1016/S1054-3139(03) 00011-0

Rude NP, Hintz WD, Norman JD, Kanczuzewski KL, Yung AJ, Hofer KD, Whitledge GW (2013) Using pectoral fin rays as a non-lethal aging structure for smallmouth bass: precision with otolith age estimates and the importance of reader experience. J Freshw Ecol 28:199-210. https://doi.org/10.1080/02705060.2012.738253

Schram ST, Fabrizio MC (1998) Longevity of lake superior lake trout. North Am J Fish Manage 18:700-703. https://doi.org/10.1577/ 1548-8675(1998)018\%3c0700:LOLSLT\%3e2.0.CO;2

Scott WB, Crossman EJ (1973) Freshwater fishes of Canada. Fish Res Bd Can 184:966

Sharp D, Bernard DR (1988) Precision of estimated ages of lake trout from five calcified structures. North Am J Fish Manage 8:367372. https://doi.org/10.1577/1548-8675(1988)008\%3c0367: POEAOL\%3e2.3.CO;2

Shuter BJ, Jones ML, Korver RM, Lester NP (1998) A general, life history based model for regional management of fish stocks: the inland lake trout (Salvelinus namaycush) fisheries of Ontario. Can J Fish Aquat Sci 55:2161-2177. https://doi.org/10.1139/f98-055

Sikstrom CB (1983) Otolith, pectoral fin ray, and scale age determinations for Arctic Grayling. Prog Fish Cult 45(4):220-223. https:// doi.org/10.1577/1548-8659(1983)45[220:OPFRAS]2.0.CO;2

Spiegel JR, Quist MC, Morris JE (2010) Precision of scales and pectoral fin rays for estimating age of highfin carpsucker, quillback carpsucker, and river carpsucker. J Freshw Ecol 25:271-278. https://doi.org/10.1080/02705060.2010.9665077
Stolarski JT, Hartman KJ (2008) An evaluation of the precision of fin ray, otolith and scale age determinations for brook trout. North Am J Fish Manage 28:1790-1795. https://doi.org/10.1577/ M07-187.1

Tyszko SM, Pritt JJ (2017) Comparing otoliths and scales as structures used to estimate ages of largemouth bass: consequences of biased age estimates. North Am J Fish Manage 37:1075-1082. https:// doi.org/10.1080/02755947.2017.1350220

Uzunova E, Ignatov K, Petrova R (2020) Comparison of age estimates from scales, fin rays, and otoliths of the introduced Peipsi whitefish, Coregonus maraenoides (Actinopterygii: Salmoniformes: Salmonidae), collected from the Iskar Reservoir (Danube River Basin). Acta Ichthyol Piscat 50:13-21. https://doi.org/10.3750/ AIEP/02521

Wellenkamp W, He JX, Vercnocke D (2015) Using maxillae to estimate ages of lake trout. North Am J Fish Manage 35:296-301. https:// doi.org/10.1080/02755947.2014.1001045

Williams AJ, Newman SJ, Wakefield CB, Bunel M, Halafihi T, Kaltavara J, Nicol SJ (2015) Evaluating the performance of otolith morphometrics in deriving age compositions and mortality rates for assessment of data-poor tropical fisheries. ICES J Mar Sci 72:2098-2109. https://doi.org/10.1093/icesjms/fsv042

Winkler AC, Duncan MI, Farthing MW, Potts WM (2019) Sectioned or whole otoliths? A global review of hard structure preparation techniques used in ageing sparid fishes. Rev Fish Biol and Fisheries 29:605-611. https://doi.org/10.1007/s11160-019-09571-1

Yaremchuk GCB (1986) Results of a nine year study (1972-80) of sport fishing exploitation of lake trout (Salvelinus namaycush) on Great Slave and Great Bear lakes, NWT: the nature of the resource and management options. Can Tech Rep Fish Aquat Sci 1436. https://cat.fsl-bsf.scitech.gc.ca/record=3856574 S6. Accessed 31 Mar 2020

Zhu X, Wastle RJ, Howland KL, Leonard DJ, Mann S, Carmichael TJ, Tallman RF (2015) A comparison of three anatomical structures for estimating age in a slow-growing subarctic population of lake whitefish. North Am J Fish Manage 35:262-270. https://doi.org/ 10.1080/02755947.2014.996683

Publisher's Note Springer Nature remains neutral with regard to jurisdictional claims in published maps and institutional affiliations. 